\title{
Effect of Health Problems on Daily Activities Likert Scale
}

National Cancer Institute

\section{Source}

National Cancer Institute. Effect of Health Problems on Daily Activities Likert Scale. NCI

Thesaurus. Code C123293.

A scale for the subjective scoring of the effect of an individual's health problems on their ability to do daily activities that ranges from 0: Health problems had no effect on my daily activities to 10: Health problems completely prevented me from doing my daily activities. 